\title{
Human effect monitoring in cases of occupational exposure to antineoplastic drugs: a method comparison
}

Sebastian Kevekordes, Thomas W Gebel, Martin Hellwig, Wendelin Dames, Hartmut Dunkelberg

\begin{abstract}
Objectives-To investigate whether DNA damage increased in subjects possibly exposed to high amounts of antineoplastic agents.

Methods-The level of genetic damage was determined in peripheral mononuclear blood cells with the sister chromatid exchange test, the alkaline elution technique, and the cytokinesis block micronucleus test.

Results-The supposed increased exposure of the study subjects was caused by a malfunction of a safety hood resulting in leakage of air during preparation of an infusion of an antineoplastic drug. Two months after a new safety hood was installed, the frequencies of micronuclei and sister chromatid exchanges of exposed nurses $(n=10)$ were still significantly increased when compared with a matched control group $(p<0.01$ and $p<0.05$, one sided Wilcoxon test, respectively). In a second examination seven months later, the frequency of micronuclei had significantly decreased to control values $(p<0.05$, one sided Wilcoxon test, $n=6)$. Moreover, the study subjects who smoked $(n=8)$ had significantly increased frequencies of micronuclei and sister chromatid exchanges $(p<0.01$ and $p<0.05$, one sided $U$ test, respectively). No differences in the rate of DNA damage could be detected with the alkaline elution technique.

Conclusions-Control measures on the level of biological effect should be performed regularly to ensure maximum safety precautions for workers potentially exposed to genotoxic agents.
\end{abstract}

(Occup Environ Med 1998;55:145-149)

Occupational Health,

University of

Goettingen,

Robert-Koch-Strasse

40, D-37073

Goettingen, Germany

W Dames

Correspondence to:

Dr Thomas Gebel, Medical Institute of General Hygiene and Environmental Health (Allgemeine Hygiene und

Umweltmedizin), University of Goettingen, Windausweg 2, 37073 Goettingen,

Germany. Tel: 0049551

394973; Fax: 0049551

394957.

Accepted 5 September 1997

anticancer drugs possess genotoxi activity in experimental systems, or they are even carcinogenic to humans. ${ }^{1-4}$ Increased occupational exposures can be expected for subjects employed in the manufacture, preparation, and administration of these drugs. To minimise potential risks, safety precautions such as wearing surgical masks, gloves, gowns, and hair covers and using laminar flow safety hoods (class II) are recommended by national and international authorities..$^{5-7}$ As several handling guidelines were introduced, the safe preparation and administration of antineoplas- tic drugs is generally good. Increased exposure to antineoplastic agents is thus generally low, but it can occasionally or accidentally be high. To ensure maximum occupational safety, the measurement of biological markers is deemed appropiate for the monitoring of such exposure patterns. ${ }^{4}$

Various methods of monitoring biological effects have been established. Although all of these do not point to a particular stage in the development of cancer, they should be considered as an internal dosimeter in the detection of increased genotoxic and presumably also carcinogenic risks. $^{348}$ Among these approaches are the detection of chromosomal aberrations, sister chromatid exchanges, micronuclei, and the alkaline elution technique. Furthermore, urine mutagenicity and excretion of thioethers have been measured. ${ }^{34}$ In general, the results were heterogenous because of differing sensitivities of the test systems and the extent and type of exposure. In the present study, the cytokinesis block micronucleus assay was compared with the sister chromatid exchange and the alkaline elution technique for usefulness in human effect monitoring in a case of exposure to an anticancer drug.

\section{Materials and methods}

A safety check in a hospital's cancer department showed the malfunction of a safety hood resulting in air flowing from the hood along the arms of the person preparing infusions of antineoplastic drugs. This possibly resulted in an increased exposure of the employees to antineoplastic agents. The safety hood had thus to be exchanged to ensure maximum occupational safety. We first became involved two months later.

Blood from the study subjects was collected by venepuncture at the work site and was processed within three hours. Heparinised blood $(10 \mathrm{ml})$ was cooled before processing and used for the alkaline elution and the micronucleus test, whereas citrate blood was kept at room temperature and used for the sister chromatid exchange test.
DESCRIPTION OF STUDY SUBJECTS

Ten nurses from a hospital's cancer department aged 23-38 years who could have been exposed to high amounts of antineoplastic agents agreed to participate in our investigation. Six of them agreed to participate in a second examination seven months later. A questionnaire was used for data collection which included information on age, drug use, 
Survey of subject data amd the individual frequencies of sister chromatid exchanges and micronuclei

\begin{tabular}{|c|c|c|c|c|c|c|c|c|}
\hline \multirow{2}{*}{\multicolumn{2}{|c|}{ Proband No }} & \multirow{3}{*}{$\frac{\text { Age (y) }}{\text { Exposed/matched }}$} & \multirow{3}{*}{$\begin{array}{l}\text { Smoking } \\
\text { habit }\end{array}$} & \multirow{2}{*}{\multicolumn{2}{|c|}{$\begin{array}{l}\text { Mean sister chromatid } \\
\text { exchanges/metaphase }\end{array}$}} & \multicolumn{3}{|c|}{ Mean micronuclei $/ 10^{3}$ binucleate lymphocytes } \\
\hline & & & & & & \multicolumn{2}{|c|}{ First examination } & \multirow{2}{*}{$\begin{array}{l}\text { Second examination } \\
\text { Exposed }\end{array}$} \\
\hline Exposed & Matched & & & Exposed & Matched & Exposed & Matched & \\
\hline 1 & 11 & $37 / 37$ & NS & 6.84 & 8.04 & 20 & 11 & $\mathrm{NE}$ \\
\hline 2 & 12 & $24 / 25$ & $\mathrm{~S}$ & 9.94 & 9.43 & 10 & 9 & 10 \\
\hline 3 & 13 & $33 / 32$ & $\mathrm{~S}$ & 6 & 7.43 & 22 & 19 & 15 \\
\hline 4 & 14 & $29 / 30$ & NS & 8.11 & 5.61 & 13 & 9 & $\mathrm{NE}$ \\
\hline 5 & 15 & $23 / 23$ & NS & 8.84 & 5.91 & 13 & 7 & 9 \\
\hline 6 & 16 & $28 / 29$ & NS & 6.55 & 5.54 & 14 & 11 & 8 \\
\hline 7 & 17 & $25 / 24$ & NS & 8.26 & 6.27 & 12 & 6 & $\mathrm{NE}$ \\
\hline 8 & 18 & $38 / 40$ & $S$ & 7.92 & 8.23 & 21 & 23 & $\mathrm{NE}$ \\
\hline 9 & 19 & $32 / 32$ & NS & 9.24 & 4.51 & 9 & 4 & 9 \\
\hline 10 & 20 & $33 / 34$ & S & 11.4 & 7.98 & 21 & 14 & 20 \\
\hline \multicolumn{9}{|c|}{ All probands: } \\
\hline Mean & & & & 8.3 & 6.9 & 15.5 & 11.3 & 11.8 \\
\hline Mediar & & & & 8.2 & 6.9 & 13.5 & 10.0 & 9.5 \\
\hline $\mathrm{p}$ Value & & & & \multicolumn{2}{|c|}{$0.02 v$ matched } & \multicolumn{2}{|c|}{$0.005 v$ matched } & $0.03 v$ first examination \\
\hline
\end{tabular}

$\mathrm{NE}=$ not examined; $\mathrm{NS}=$ non-smoker; $\mathrm{S}=$ smoker.

cigarettes smoked each day, lifetime smoking habits, contact with other genotoxins, and weekly frequency of handling cytostatic drugs during the past three months.

A control group was collected by matching sex, age, and intensity of smoking (five additional cigarettes a day were accepted for the respective control subjects). All controls had no known increased exposure to any cytostatic agents; nor was there any other increased exposure to genotoxic agents known besides smoking.

CYTOKINESIS BLOCK MICRONUCLEUS TEST

The micronucleus test was performed as described by Fenech and Morley ${ }^{9}$ with some modifications. Heparinised whole blood (500 $\mu \mathrm{l})$ was cultured in round bottomed plastic tubes in $4.5 \mathrm{ml}$ culture medium (RPMI1640, Biochrom Berlin, Germany) supplemented with $15 \%$ calf serum, penicillin $(100 \mathrm{U} / \mathrm{ml})$, and streptomycin $(100 \mu \mathrm{g} / \mathrm{ml})$ at $37^{\circ} \mathrm{C}$ in a humidified atmosphere containing $5.0 \% \mathrm{CO}_{2}$. Cell mitosis was stimulated with phytohaemagglutinin (final concentration $5 \mu \mathrm{g} / \mathrm{ml}$ ) (Biochrom Berlin, Germany). Forty four hours after stimulation with phytohaemagglutinin, cytochalasin B was added to the cultures to yield a final concentration of $4.5 \mu \mathrm{g} / \mathrm{ml}$. Twenty six hours later the cells were harvested. After two minutes of treatment with hypotonic solution $(0.07 \mathrm{M} \mathrm{KCl}$ and $0.15 \mathrm{M} \mathrm{NaCl} ; 4+1)$ the cells were fixed in methanol and acetic acid $(3+1)$ for 30 minutes at $4^{\circ} \mathrm{C}$ and sedimented at $155 \mathrm{~g}$ for 10 minutes. The step of fixation was

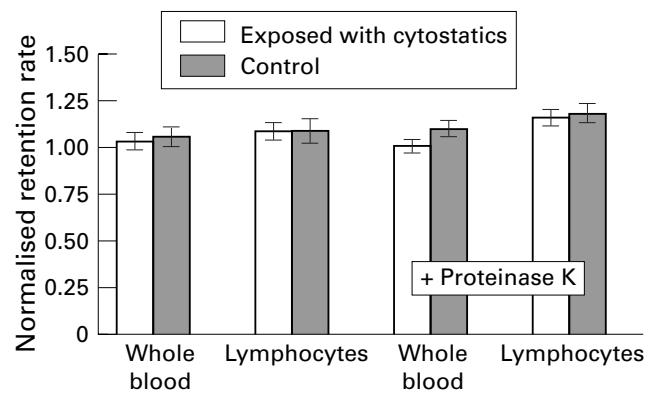

Figure 1 Normalised DNA retention rates (mean (SEM)) in the alkaline elution technique of 10 nurses handling antineoplastic agents and their respective matched controls. Each bar represents 10 subjects. repeated twice. Microscope slides were prepared in duplicate and were air dried and stained with $5 \%$ Giemsa solution at $\mathrm{pH} 6.8$ for 10 minutes. Micronuclei as defined by criteria summarised by Fenech ${ }^{10}$ were scored in 1000 binucleate cells with two nuclei of roughly equal size. The nuclear division index (NDI) was calculated as in Eastmond and Tucker ${ }^{11}$ as:

$\mathrm{NDI}=(\mathrm{MI}+2 \mathrm{MII}+3 \mathrm{MIII}+4 \mathrm{MIV} / 1000$ cells counted in total)

where MI-IV represents the number of lymphocytes with one to four nuclei.

SISTER CHROMATID EXCHANGE ANALYSIS

The sister chromatid exchange analysis was performed as described in Kevekordes et al. ${ }^{12}$ Briefly, $0.3 \mathrm{ml}$ whole citrate blood was added to $5 \mathrm{ml}$ medium containing phytohaemagglutinin (Biochrom Berlin, Germany). All cultures were incubated at $37^{\circ} \mathrm{C}$ in complete darkness for 72 hours. At 24 hours bromodeoxyuridine was added in a final concentration of $6 \mu \mathrm{g} / \mathrm{ml}$. Colcemid in a final concentration of $0.4 \mu \mathrm{g} / \mathrm{ml}$ was added two hours before harvesting. Microscope slides were air dried, prepared according to the FPG technique, ${ }^{13}$ and coded. A total of 30 second division metaphases from each culture was scored for sister chromatid exchanges. The proliferation index was calculated by analysing 100 cells as follows:

$\mathrm{PRI}=(\mathrm{MI}+2 \mathrm{MII}+3 \mathrm{MIII} /$ cells counted in total)

where MI-III represents the number of lymphocytes in the first, second, or third generation.

ALKALINE ELUTION METHOD

Peripheral mononuclear blood cells were isolated from heparinised venous blood by ficoll metrizoate centrifugation according to Boyum. ${ }^{14}$ The alkaline elution technique of Kohn et $a l^{15}$ was performed with some modifications as described in Gebel et al. ${ }^{16}$

Briefly, either $0.5 \mathrm{ml}$ heparinised fresh whole blood diluted with $15 \mathrm{ml}$ erythrocyte lysing solution $\left(780 \mathrm{mM} \mathrm{KCl}, 50 \mathrm{mM} \mathrm{KHCO}_{3}, 5\right.$ mM EDTA) or 1 million mononuclear blood cells in $1 \mathrm{ml}$ phosphate buffered saline were poured on to a polycarbonate filter (Costar, Bodenheim, Germany; $13 \mathrm{~mm}$ diameter, $2 \mu \mathrm{m}$ pore size). Cells were lysed with $3 \mathrm{ml} 10 \mathrm{mM}$ 

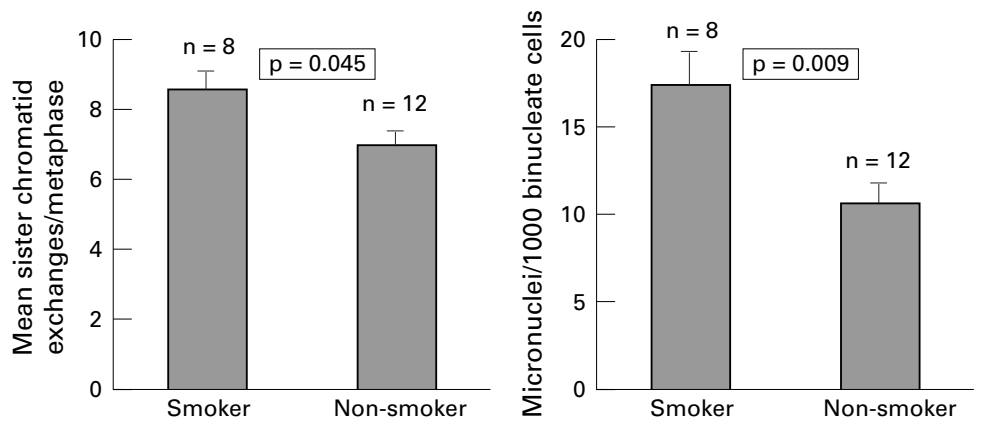

Figure 2 Frequencies of sister chromatid exchanges and micronuclei (mean (SEM)) of all subjects after stratification by smoking status, compared by the one sided $U$ test. The respective number of people examined is given above each bar.

EDTA, 0.5\% (w/v) Triton X-100, $2 \mathrm{M} \mathrm{NaCl}$ (pH 10.0) for 60 minutes. Then the cells were washed with $6 \mathrm{ml} 10 \mathrm{mM}$ EDTA ( $\mathrm{pH}$ 10.0) for 90 minutes. The elution was performed at $10^{\circ} \mathrm{C}$ in the dark with a flow rate of $1.5 \mathrm{ml} / \mathrm{h}$ with $5 \mathrm{M} \mathrm{NaCl}, 50 \mathrm{mM}$ EDTA (pH 12.6). A fraction was collected for 10 hours beginning 20 minutes later, the filters were sonicated in $15 \mathrm{ml}$ elution buffer for $2 \times 10$ minutes to remove the retained DNA. The DNA was measured fluorometrically with Hoechst 33258 as described in Sterzel et $a l^{17}$ with a Skalar San plus system (Skalar, Breda, The Netherlands). The samples were measured in triplicate. As internal standard, a whole blood sample of one non-exposed subject was used in each whole blood alkaline elution, in each elution with isolated lymphocytes $10^{6}$ cells of an untreated standard of the cell line V79 were used. The normalised retention rate was calculated as a proportion of each sample to the respective internal standard.

STATISTICAL EVALUATIONS

The Wilcoxon test for paired data and the $U$ test (one sided) according to Wilcoxon, Mann, and Whitney were used to evaluate significances between the variables examined. Mean values (SEM) are presented.

\section{Results}

All nurses and their matched control subjects were asked about medication used in the past three months. Three subjects received levothyroxine, one iodide, and two oral contraceptives; no confounding effect on the individual frequencies of micronuclei and sister chromatid exchanges and on the retention rate in the alkaline elution were found. The antineoplastic agents cisplatin, cyclophosphamide, iphosphamide, vincristin, doxorubicin, dactinomycin, cytosine arabinoside, and methotrexate were handled by the study nurses for one to five days each working week. All subjects said that they had taken the recommended safety precautions into consideration during drug preparation. Gloves, surgical masks, gowns, and hair covers were worn. As well as exposure through drug preparation, all nurses had direct contact with their cancer patients.

The table shows individual data on age and smoking habits, and frequencies of micronuclei and sister chromatid exchanges. The first examination was carried out two months after installation of a new safety hood. Six of the 10 subjects agreed to participate in a second micronucleus test analysis nine months after the reduction of the supposedly increased exposure. In the first examination, alkaline elution was carried out with either fresh whole blood or isolated peripheral lymphocytes (fig 1). Fresh whole blood consists of two thirds of short living non-lymphocyte nuclear blood cells-for example, monocytes and granulocytes - and has the advantage of detecting acute effects on DNA. By contrast, the use of isolated long living peripheral lymphocytes shows a chronic or subchronic effect in the DNA. Proteinase K was used to identify a possible generation of DNA-protein crosslinks. No significant difference could be found in the rates of DNA damage in the alkaline elution technique in any of the experimental setups.

In contrast, increased frequencies of sister chromatid exchanges were found for the nurses with a mean of 8.3 versus 6.9 in the matched controls (table). A greater difference was noticed in the micronucleus test with a mean of 15.5 versus 11.3 micronuclei per 10 binucleate lymphocytes. Both these differences were significant $(p=0.02$ and $p=0.005$ in the one sided Wilcoxon test, respectively). In the second examination seven months later-that is, nine months after the end of exposure-the frequencies of micronuclei of the six nurses participating were shown to have significantly decreased to control values (mean values 15.5 and 11.8 micronuclei per 10 binucleate lymphocytes, each $n=6 ; p=0.034$, in the one sided Wilcoxon test). Furthermore, the frequency of micronuclei was no longer significantly different from the frequency of micronuclei of the matched controls. When the study subjects were stratified by smoking status, it was shown that smokers had significantly increased frequencies of micronuclei and sister chromatid exchanges (mean values $8.5 v 7.0$ sister chromatid exchanges per metaphase and $17.4 v 10.8$ micronuclei per 10 binucleate lymphocytes; $\mathrm{p}=0.045$ and $\mathrm{p}=0.009$ in the one sided $U$ test, respectively; fig 2). Because the control subjects had been selected by matching, the group of smokers and the group of non-smokers both consisted of $50 \%$ exposed and non-exposed subjects, so exposure as a factor of influence is held constant and could not have had a confounding influence on this result. 
In conclusion, the genetic damage was associated with smoking and with occupational exposure to the cytostatic drugs in the micronucleus test and the sister chromatid exchange test. The extent of effects was slightly greater in the micronucleus test than in the sister chromatid exchange test.

\section{Discussion}

Biological exposure monitoring to measure the content of anticancer drugs in blood or urine was not performed for two reasons. Firstly, the supposed exposure of the study subjects had been reduced two months before, which suggested that the greatest part of antineoplastic agents incorporated should have been excreted from the body. Secondly, because the individual pattern of exposure to anticancer drugs was different for each study participant, chemicoanalytical biomonitoring did not seem practicable.

There are many factors influencing the outcome of human biomonitoring studies. To name only a few, lifestyle, differences in individual susceptibility and flaws in the study design may have undesired impacts on study outcomes. The safety precautions practised will be different between people and between working places. The correct handling of and behaviour at safety hoods is one further important determinant for the respective internal exposure of each person. Thus, it is obvious that the results of respective studies cannot be uniform.

For instance, Anwar et $a l^{18}$ found a significant increase in the mean number of micronuclei and chromosome aberrations for nurses compared with matched controls, whereas a significantly increased incidence of micronuclei was not found for nurses occupationally exposed to cytostatic drugs. ${ }^{19}$ Studies of nurses handling different chemotherapeutic drugs daily showed increased frequencies of sister chromatid exchanges compared with office workers. ${ }^{2021}$ Also, structural chromosomal aberrations were found to be significantly higher in a group of oncology nurses than in laboratory workers and hospital clerks serving as the respective control groups. ${ }^{22}$ Dicentric chromosomes but not chromosomal breaks and sister chromatid exchanges were increased in nurses handling cytostatic drugs without the use of safety covers compared with those who did use safety covers. ${ }^{23}$ In contrast, Barale et $a l^{24}$ did not find differences in the frequencies of sister chromatid exchange between a group handling cytostatic drugs and a control group. Roth et $a l^{25}$ compared chromosomal aberrations, sister chromatid exchanges, and micronuclei in two examinations before and after one year of working with cytostatic drugs in six nonsmoking female pharmacists. As a control, an age matched group of six non-smoking female hospital workers not dealing with cytostatic drugs was simultaneously sampled. There were no significant differences between the two groups for any of the three end points at either sampling time.

Fuchs et $a l^{26}$ reported increased DNA damage with the alkaline elution technique for a group of nurses handling anticancer drugs who did not respect any safety precautions during drug preparation. In a second examination six months later and after these nurses had started taking safety precautions into account, the rates of DNA damage in peripheral mononuclear blood cells had decreased to control levels. Increased DNA damage in nurses working according to the respective precautions was not detected. An explanation for the negative findings with the alkaline elution technique obtained in the present study may be that the nurses had not been highly exposed. They respected safety precautions but were working with a defective safety hood. Confirming our results, Fuchs et al could not find differences in DNA damage between 42 smokers and 82 non-smokers. However, in another study, a $13 \%$ higher rate of DNA strand breaks was reported in 137 smokers compared with 138 non-smokers. ${ }^{27}$ In all, these data seem to indicate a lack of sensitivity of the alkaline elution techique for human biomonitoring.

Xue et $a l^{2}$ reported that smoking significantly increased the frequency of micronuclei in lymphocytes. Giorgio et $a l^{29}$ assessed the numbers of micronuclei in cytokinesis blocked lymphocytes of 200 male and female healthy donors not occupationally exposed to genotoxic substances. Smoking habits induced micronuclei significantly. Studies investigating the impact of tobacco smoking on the incidences of sister chromatid exchanges have been numerous. In general, increased frequencies of sister chromatid exchange were found for smokers. ${ }^{30}$ The effect of tobacco smoking found in this study conforms well to these data.

We thank K Kleinschmidt and P Birkenkamp for their excellent technical expertise.

1 International Agency for Research on Cancer. Monographs on the evaluation of carcinogenic risks to humans. Some antine-
oplastic and immunosuppressive agents. Lyon: IARC, 1981;26.

2 International Agency for Research on Cancer. Monographs on the evaluation of carcinogenic risks to humans. Pharmaceuon the evaluation of carcinogenic risks to hum
tical drugs. Lyon: IARC, 1990;50:47-142.

3 Sorsa M, Hemminki K, Vainio H. Occupational exposure to anticancer drugs. Potential and real hazards. Mutat Res 1985;154:135-49.

4 Sorsa M, Anderson D. Monitoring of occupational exposure to cytostatic anticancer agents. Mutat Res 1996;355:25361 .

5 BAGUV (Bundesverband der Unfallversicherungsträger der öffentlichen Hand) Sichere Handhabung von Zytostatika. Munich, Germany: BAGUV, 1986. (GUV 28.3, 12/86.)

6 BAGUV (Bundesverband der Unfallversicherungsträger der öffentlichen Hand) Richtlinien für Laboratorien. Munich, Germany: BAGUV, 1993. (GUV 16.17, 10/93.)

7 European Society of Clinical Pharmacy. 2nd Interdisciplinary workshop on handling cytostatic drugs. Hannover, Germany:
ESCP, 1990 .

8 Arlett C, Ashby J, Fiedler R, et al. Micronuclei: origins, applications and methodologies - a workshop sponsored by he Health and Safety Executive held in Manchester, 23-25 May, 1989. Mutagenesis 1989;4:482-5.

9 Fenech M, Morley AA. Measurement of micronuclei in lymphocytes. Mutat Res 1985;147:29-36.

10 Fenech $M$. The cytokinesis-block micronucleus technique: a detailed description of the method and its application to genotoxicity studies in human populations. Mutat Res 1993;285:35-44.

11 Eastmond DA, Tucker JD. Identification of aneuploidyinducing agents using cytokinesis-blocked human lym-
phocytes and an anti-kinetochore antibody. Environ Mol Mutagen 1989;13:34-43.

12 Kevekordes S, Gebel T, Pav K, et al. Genotoxicity of selected pesticides in the mouse bone-marrow micronucleus test and in the sister-chromatid exchange test with human lymphocytes in vitro. Toxicol Lett 1996;89:35-42.

13 Perry P, Wolff S. New Giemsa method for differential staining of sister chromatid exchanges. Nature 1974;251:156-8. 
14 Boyum A. Separation of white blood cells. Nature 1964;204 793.

15 Kohn KW, Ewig RAG, Erickson LC, et al. Measurement of strand breaks and cross-links by alkaline elution. In: Friedberg EC, Hanawalt PC, eds. DNA repair. New York: Dekker, 1980:379-401.

16 Gebel T, Kevekordes S, Schaefer J, et al. Assessment of a possible genotoxic enviromental risk in sheep bred on grounds with strongly elevated contents of mercury, arsenic and antimony. Mutat Res 1996;368:267-74.

17 Sterzel W, Bedford P, Eisenbrand G. Automated determination of DNA using the fluorochrome Hoechst 33258. Anal Biochem 1985;147:462-7.

18 Anwar WA, Salama SI, el-Serafy MM, et al. Chromosomal aberrations and micronucleus frequency in nurses occupationally exposed to cytotoxic drugs. Mutagenesis 1994;9: 315-7.

19 Thiringer G, Granung G, Holmen A, et al. Comparison of methods for the biomonitoring of nurses handling antitumor drugs. Scand $\mathcal{F}$ Work Environ Health 1991;17: antitur 8

20 Norppa $\mathrm{H}$, Sorsa $\mathrm{M}$, Vainio $\mathrm{H}$, et al. Increased sister chromatid exchange frequencies in lymphocytes of nurses handling cytostatic drugs. Scand $\mathcal{f}$ Work Environ Health 1980;67:229-301.

21 Sorsa M, Norppa H, Vainio H. Induction of sister chromatid exchanges among nurses handling cytostatic drugs. In Bridges BA, Butterworth BE, Weinstein IB, eds. Indicators of genotoxic exposure. Cold Spring Harbor, New York: Cold Spring Harbor Laboratory, 1982:341-50. (Banbury Report 13.)

22 Nikula E, Kiviniitty K, Leisti J, et al. Chromosome aberrations in lymphocytes of nurses handling cytostatic agents. Scand 7 Work Environ Health 1984;10:71-4.
23 Oestreicher U, Stephan G, Glatzel M. Chromosome and SCE analysis in peripheral lymphocytes of persons occupationally exposed to cytostatic drugs handled with and without use of safety covers. Mutat Res 1990;242:271-7.

24 Barale R, Sozzi G, Toniolo P, et al. Sister-chromatid exchanges in lymphocytes and mutagenicity in urine of nurses handling cytostatic drugs. Mutat Res 1985;157:23540.

25 Roth S, Norppa H, Järventaus H, et al. Analysis of chromosomal aberrations, sister-chromatid exchanges and micronuclei in peripheral lymphocytes of pharmacists before and after working with cytostatic drugs. Mutat Res 1994;325: 157-62.

26 Fuchs J, Hengstler JG, Jung D, et al. DNA damage in nurses handling antineoplastic agents. Mutat Res 1995; 342:17-23.

27 Oesch F, Hengsler JG, Fuchs J. Cigarette smoking protects mononuclear blood cells of carcinogen exposed workers from additional work exposure-induced DNA single strand breaks. Mutat Res 1994;321:175-85.

28 Xue KX, Wang S, Ma GJ, et al. Micronucleus formation in peripheral-blood lymphocytes from smokers and the influence of alcohol and tea drinking habits. Int f Cancer 1992; 50:702-5.

$29 \mathrm{Di}$ Giorgio C, De Méo MP, Laget $M$, et al. The micronucleus assay in human lymphocytes: screening for inter-individual variability and application to biomonitorinter-individual variability and app
ing. Carcinogenesis 1994;15:313-7.

30 Benhamou S, Pot-Deprun J, Sancho-Garnier H, et al. Sister chromatid exchanges and chromosomal aberrations in lymphocytes of nurses handling cytostatic agents. Int 7 Cancer 1988;41:350-3.

\section{Occupational and Environmental Medicine - http://www.occenvmed.com}

Visitors to the world wide web can now access Occupational and Environmental Medicine either through the BMJ Publishing Group's home page (http://www.bmjpg.com) or directly by using its individual URL (http://www.occenvmed.com). There they will find the following:

- Current contents list for the journal

- Contents lists of previous issues

- Members of the editorial board

- Subscribers' information

- Instructions for authors

- Details of reprint services.

A hotlink gives access to:

- BMJ Publishing Group home page

- British Medical Association website

- Online books catalogue

- BMJ Publishing Group books.

The web site is at a preliminary stage and there are plans to develop it into a more sophisticated site. Suggestions from visitors about features they would like to see are welcomed. They can be left via the opening page of the BMJ Publishing Group site or, alternatively, via the journal page, through "about this site". 